\title{
Stabilization of Soft Clay by Using Diapers Back Sheet Layer Wastes
}

\author{
Ahmad Hakimi Mat Nor ${ }^{1}$, Faizal Pakir ${ }^{2, *}$, Muhammad Arif Azraei Izzudin ${ }^{2}$, Salman Salim ${ }^{1}$, \\ Mohd Erwan Sanik ${ }^{1}$, Masiri Kaamin ${ }^{1}$, and Mohd Firdaus Md Dan $^{2}$, Mohd Khairy \\ Burhanudin $^{2}$ \\ ${ }^{1}$ Centre for Diploma Studies, Universiti Tun Hussein Onn Malaysia (Kampus Pagoh) KM 1,Jalan \\ Panchor,84000,Muar, Johor, Malaysia \\ ${ }^{2}$ Faculty of Civil and Environmental Engineering, Universiti Tun Hussein Onn Malaysia, 86400 Batu \\ Pahat, Johor, Malaysia
}

\begin{abstract}
This research focus on improving the weaknesses of soft clay soils by using proper recycled material as a stabilization agent for strengthening purpose. Therefore, Diaper's Back Sheet Layer Wastes (DBSLW) were used as the agent of soil stabilization. In this study, series of laboratory test were conducted to evaluate the optimum size and content of DBSLW as a strip reinforcement to increase the strength of Batu Pahat Soft Clay (BPSC). Testing program involves obtaining the physical properties of BPSC followed by California Bearing Ratio (CBR) test to determine the strength of BPSC with and without the addition of DBSLW. Result shows that the optimum size for DBSLW is $10 \mathrm{~mm}$ x $30 \mathrm{~mm}$ while the optimum content is $0.5 \%$. At $15 \mathrm{~mm}$ penetration, sample with diapers strip of $10 \mathrm{~mm} \times 30 \mathrm{~mm}$ dimension record $4.10 \mathrm{kN}$ CBR value compare to $1.64 \mathrm{kN} \mathrm{CBR}$ value of untreated soil, 2.5 times stronger than untreated soil. Results of CBR tests demonstrated that inclusion of DBSLW strips in soil with optimum amounts and size improved strength and deformation behavior of soils substantially. The proposed technique could be used to advantage in road construction, industrial yards, and building structure.
\end{abstract}

\section{Introduction}

Soil stabilization is the process which is used to improve the engineering properties of the soil and thus making it become more stable. Soil stabilization is required when the soil available for construction is not suitable for the intended purpose. It includes compaction, pre consolidation, drainage and many other such processes [1].

Soil Stabilization is the alteration of soils to enhance their physical properties. Stabilization can increase the shear strength of a soil and control the shrink-swell properties of a soil, thus improving the load bearing capacity of a sub-grade to support pavements and foundations. Soil Stabilization can be utilized on roadways, parking areas, site development projects, airports and many other situations where sub-soils are not suitable for construction. Stabilization can be used to treat a wide range of sub-grade materials, varying

\footnotetext{
*Corresponding author: faizalp@uthm.edu.my
} 
from expansive clays to granular materials. This process is accomplished using a wide variety of additives, including lime, fly-ash, and Portland cement. Other material byproducts used in Stabilization include lime-kiln dust (LKD) and cement-kiln dust (CKD) [1].

Stabilization in a broad sense incorporates the various methods employed for modifying the properties of a soil to improve its engineering performance. Stabilization is being used for a variety of engineering works, the most common application being in the construction of road and airfield pavements, where the main objective is to increase the strength or stability of the soil and to reduce the construction cost by making best use of locally available materials.

\section{Literature Review}

Soil fiber composites have been found effective in improving the CBR value. These studies indicated that stress-strain-strength properties of randomly distributed fiber reinforced soil are a function of fiber content and aspect ratio. Strength and load bearing capacity of soil was enhanced considerably when the soil is stabilized mechanically with short thin plastic strips of different length and content [2]. The feasibility of reinforcing soil with strips of reclaimed Diapers Back Sheet Layer Wastes (DBSLW), Polyethylene has also been investigated to a limited extent $[3,4]$. A detailed study pertaining to its use in real life problems is still quite meager. In view of the above limited studies, present study has been taken up with special reference to its feasibility for application in soil improvement. The principle of resisting action of the strips is mainly visualized as given in Figure 1 (a) and (b). In situation (a) the plunger pushes down particle $\mathrm{C}$ to occupy position in between particle $\mathrm{A}$ and $\mathrm{B}$. The strip resists the downward movement of particle $\mathrm{C}$ until slippage between soil and strip occurs resulting into development of situation (b). Thus, it is the interaction between soil and strips which causes the resistance to penetration of the plunger resulting into higher CBR values [3].

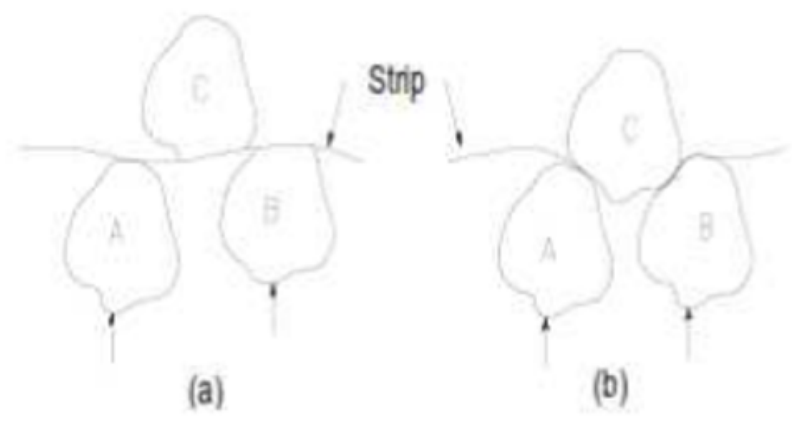

Figure 1. Schematic diagram showing position of strip (a)before and (b) after slippage between soil and strip [3]

\section{Materials and Methods}

This study was conducted on soft clay soils that were collected from the Research Centre for Soft Soils (RECESS), Universiti Tun Hussein Onn Malaysia, located at southern of the Peninsular Malaysia. The soft clay samples were taken at $1 \mathrm{~m}$ to $1.5 \mathrm{~m}$ depth. The soil was classified as highly plastic clay with plasticity index (PI) of $42 \%$, liquid limit (LL) of $72 \%$ 
and plastic limit (PL) of $30 \%$. Moreover, the natural moisture content is $87 \%$. The maximum dry density and optimum moisture content of soil as determined from the compaction test were $1340 \mathrm{kN} / \mathrm{m}^{3}$ and $30 \%$, respectively. The result almost similar with previous research by Nor et al. [6].

\subsection{Plastic waste}

Diaper's Back Sheet Layer Wastes (DBSLW) used in this study is considered as plastic waste or polyethylene. CBR behavior of DBSLW reinforced soil having strip width of $10 \mathrm{~mm}$ and a thickness of 40 micron was examined. The DBSLW were cut into different lengths of 10 $\mathrm{mm}$ [Aspect Ratio $(\mathrm{AR})=1$ ], $20 \mathrm{~mm}(\mathrm{AR}=2)$ and $30 \mathrm{~mm}(\mathrm{AR}=3)$ and 40mm $(\mathrm{AR}=4)$ for each soil sample. It is important to ensure that mould diameter remains at least 4 times the maximum strip length, which will ensure that there is sufficient room for the strips to deform freely and independent of mould confinement. The waste plastic strips to be added to the soil were considered a part of the solid fraction in the void solid matrix of the soil. The content of the strip is defined herein as the ratio of weight of strips to the weight of dry soil. The tests were conducted at various strip contents of $0.0 \%, 0.25 \%, 0.5 \%$, and $1 \%$ $[2]$.

\subsection{CBR Test Procedure}

The CBR test was based on the BS 1377: Part 2: 1990 [7]. Required amount of strips and soil were first weighed before mixing the strips with dry soil at obtained moisture content. The soil was compacted in five equal layers by applying 56 evenly distributed blows using a $4.89 \mathrm{~kg}$ rammer. A $2.5 \mathrm{~kg}$ surcharge was placed over the specimen and clamped over the base plate and the whole mould with the weight before placing under the testing machine. The penetration plunger was set at the top central surface of the soil sample by applying a seating load of $4 \mathrm{~kg}$. The dial gauge for measuring the penetration values of the plunger was fitted in position. The dial gauge of the proving ring (for load reading) and the penetration dial gauge were set to zero. The load was applied through the penetration reading of 0.0 , $0.5,1.0,1.5,2.0,2.5,3.0,4.0,4.5,7.5,10.0$ and $15.0 \mathrm{~mm}$.

\section{Results and Discussions}

Table 1 shows the soil characteristics of Batu Pahat Soft Clay which sampling at the RECESS area within UTHM campus after undergo several physical test such as Atterberg's limit, natural moisture content, natural dry unit weight and compaction.

Table 1: Physical characteristics of Soft Clay Soils

\begin{tabular}{|c|c|}
\hline Liquid Limit, (\%) & 72 \\
\hline Plastic limit, (\%) & 30 \\
\hline Plastic Index, (\%) & 42 \\
\hline Type of soil & Highly plastic clay \\
\hline Natural moisture content, (\%) & 72 \\
\hline Depth of sampling (m) & $1-1.5$ \\
\hline Optimum moisture content, (\%) & 30 \\
\hline Maximum dry density, $\left(\mathbf{k g} / \mathbf{m}^{\mathbf{3}}\right)$ & 1340 \\
\hline
\end{tabular}

The load $(\mathrm{KN})$ versus penetration $(\mathrm{mm})$ was plotted as shown in Figure 2 and Figure 3. 


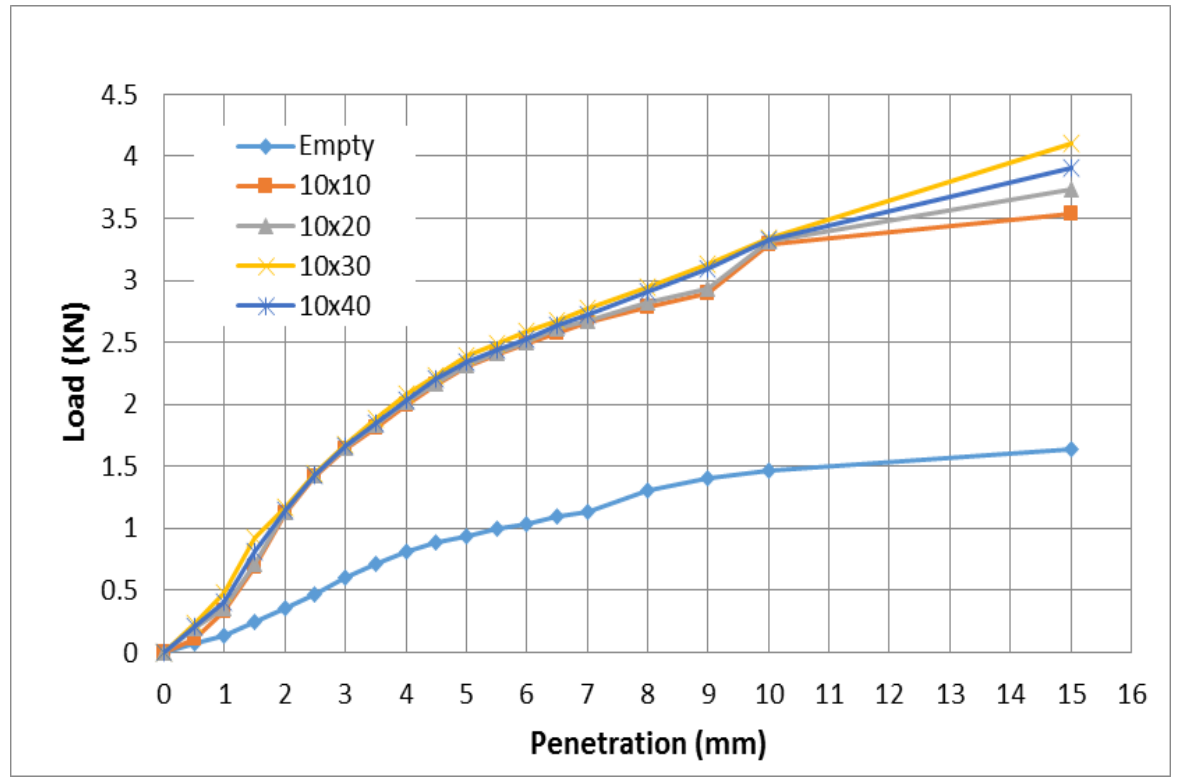

Figure 2: Result of CBR Test Using 0.5\% of Back Sheet Diapers with Different Size of Strip

Figure 2 shows the result of CBR test using $0.5 \%$ of back sheet diapers with different size of strip. The highest value recorded was the sample using size of $10 \times 30 \mathrm{~mm}$ while the lowest value recorded was the sample without strip. Moreover, this graph shows that when the size of strip increase, the value of CBR recorded also increase, although it finally stop increase when using $10 \times 40 \mathrm{~mm}$ of size strip of back sheet diapers strip. Furthermore, the CBR value recorded for without strip, using $10 \mathrm{~mm}$ x $10 \mathrm{~mm}, 10 \mathrm{~mm} \times 20 \mathrm{~mm}, 10 \mathrm{~mm}$ x $30 \mathrm{~mm}$ increased and lastly using $10 \mathrm{~mm}$ x $40 \mathrm{~mm}$ of diapers back sheet strip size are slightly decreased. Thus, the efficient and optimum size of back sheet diapers strip is 10 $\mathrm{mm} \times 30 \mathrm{~mm}$. The CBR values for unreinforced soil at $2.5 \mathrm{~mm}$ and $5 \mathrm{~mm}$ are $3.55 \%$ and $4.66 \%$ respectively while the CBR values for reinforced soil using $10 \mathrm{~mm} \times 10 \mathrm{~mm}$ are $10.73 \%$ and $11.52 \%$ respectively. Furthermore, the CBR values for reinforced soil using 10 $\mathrm{mm} \times 20 \mathrm{~mm}$ are $10.80 \%$ and $11.62 \%$ respectively, CBR values for soil reinforced using 10 $\mathrm{mm} \times 30 \mathrm{~mm}$ are $10.88 \%$ and $11.97 \%$ respectively and lastly the CBR values for reinforced soil using $10 \mathrm{~mm}$ x $40 \mathrm{~mm}$ are $10.80 \%$ and $11.72 \%$ respectively. Thus the reinforced soil with $10 \times 30 \mathrm{~mm}$ is 2.5 times stronger than unreinforced soil. [3]. In summary, the mixed of uniformly distributed DBSLW in soil increased the piston load at a given penetration considerably. These figure also prove that inclusion of DBSLW increases the CBR value appreciably. This figure reveals that the $0.5 \%$ content of $10 \mathrm{~mm}$ x $30 \mathrm{~mm}$ size strip was the optimum size and gave the maximum bearing capacity. 


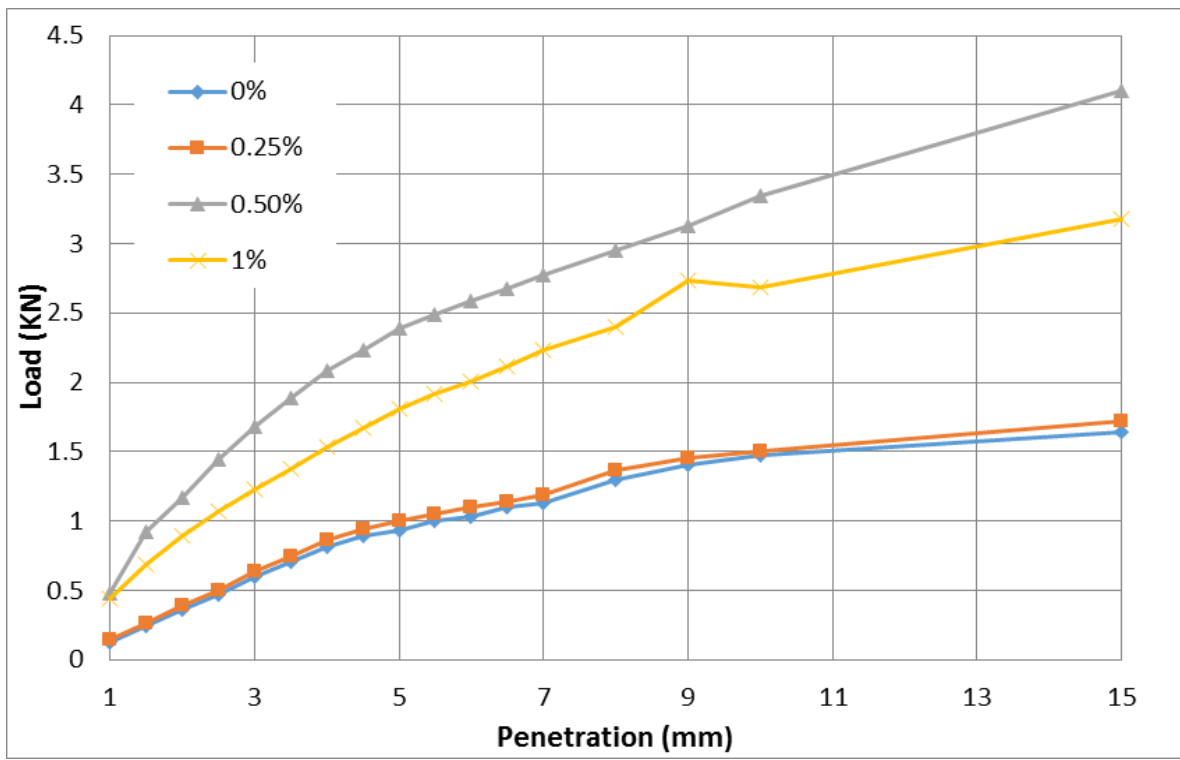

Figure 3: Result of CBR Test Using $10 \mathrm{~mm}$ x $30 \mathrm{~mm}$ Size of Strip with Different Proportion

Figure 3 shows the result of CBR test using $10 \mathrm{~mm}$ x $30 \mathrm{~mm}$ size of strip with different proportion. The highest value recorded was the sample using size of $0.5 \%$ while the lowest value recorded was the sample without strip. Moreover, this graph shows that when the percentage of proportion increase, the value of CBR recorded also increase, although it finally stop increase when using $1 \%$ of diapers back sheet strip proportion. Furthermore, the CBR value recorded for without strip and using $0.25 \%$ of diapers back sheet strip proportion not change too much. Thus, the efficient and optimum proportion of back sheet diapers strip is $0.5 \%$. The CBR values for unreinforced soil at $2.5 \mathrm{~mm}$ and $5 \mathrm{~mm}$ are 3.55 $\%$ and $4.66 \%$ respectively while the CBR values for reinforced soil using $0.25 \%$ strip content are $3.78 \%$ and $5.01 \%$ respectively. Furthermore, the CBR values for reinforced soil using $0.5 \%$ strip content are $10.88 \%$ and $11.97 \%$ respectively and lastly the CBR values for reinforced soil $1 \%$ strip content are $8.08 \%$ and $9.07 \%$ respectively. Thus the reinforced soil using $0.5 \%$ strip content is 2.5 times stronger than unreinforced soil [3]. In summary, as the soil sheared during penetration, strip fixed in the soil by friction, elongated and together provided strength against the deformation. Deformation of the samples being predominantly shear in nature, the CBR value can be regarded as an indirect measure of strength. Results of CBR tests demonstrated that inclusion of DBSLW strips in soil with appropriate amounts and size improved strength and deformation behavior of soils substantially [3]. 


\section{Conclusions}

In conclusion, DBSLW Polyethylene was diagnosed as a significant stabilizing agent for soft soil. The findings can be summarized as follow :

- It proves that DBSLW is a good admixture for soil stabilization.

- The addition of stabilizing agent to local soil increases the CBR value.

- The maximum improvement in CBR is obtained while using $0.5 \%$ using Diapers Back Sheet Layer Wastes having size of $(10 \mathrm{~mm} \times 30 \mathrm{~mm})$ which is $(\mathrm{AR}=3)$.

- The CBR value at (10 mm x $40 \mathrm{~mm})$ with $0.5 \%$ plastic strip was slightly decreased.

- The reinforcement benefit increases with an increase in size and percentage of strip content up to certain limit, and beyond that it reduces its strength.

- The maximum CBR value of a reinforced system is approximately 2.50 times stronger than that of an unreinforced system.

\section{Acknowledgement}

The authors gratefully acknowledged the Office for Research, Innovation, Commercialization, and Consultancy Management (ORICC), Universiti Tun Hussein Onn Malaysia (UTHM), Johor for their financial support.

\section{References}

1. Amin Esmaeil Ramaji, A Review on the Soil Stabilization Using Low-Cost Methods, 8(4): 2193-2196, (2012).

2. Rituparna Das, KankanaMajhi, ChampaKhatun, and ArunabhaMaiti, Soil "Stabilization using Plastic Strips of Varied Sizes by enhancing the Bearing Capacity", International Journal of Scientific \& Engineering Research, Volume 8, Issue 3, (2017).

3. Megnath Neopaney, Ugyen, Kezang Wangchuk, Sherub Tenzin, "Stabilization of Soil by Using Plastic Wastes", International Journal of Emerging trends in Engineering and Development, ISSN 2249-6149 Issue 2, Vol.2 (2012).

4. Ajmal. K.K, Lisha. V.P, Neethu. A, Thahseeb. P.K, Vaseela. C.P, Noushad. K, "An Experimental Study on Partial Replacement of Soil with Plastic Granules", International Journal of Scientific \& Engineering Research, Vol. 7, Issue 4, (2016).

5. Sharan Veer Singh, and Mahabir Dixit, "Stabilization of Soil by Using Waste Plastic Material: A Review", International Journal of Innovative Research in Science, Engineering and Technology, Vol. 6, Issue 2, (2017)

6. A. H. M. Nor, F. Pakir, A. Arifin, and M. E. Sanik, "Stabilization of Batu Pahat Soft Clay by Combination Between TX-85 and SH-85 Stabilizers", J. Adv. Res. Mater. Sci., vol. 14, no. 1, pp. 1-7, (2015)

7. BS 1377: Part 2: 1990. Geotechnical Laboratory Sheet. Test of Water Absorption, Atterberg's limit and Compaction test. 